\title{
The vacuolar ATPase proton pump is present on intracellular vacuoles induced by Helicobacter pylori
}

\author{
E. PAPINI, E. GOTTARDI, B. SATIN, M. DE BERNARD, P. MASSARI*, J. TELFORD*, R. RAPPUOLI*, \\ S. B. SATO† and C. MONTECUCCO
}

Dipartimento di Scienze Biomediche, University of Padova, Via Trieste 75, 35121 Padova, Italy, * Centro Ricerche IRIS, Via Fiorentina 1, 53100 Siena, Italy and †Department of Biophysics, Faculty of Sciences, Kyoto University Kyoto, Japan

\begin{abstract}
Cytotoxic strains of Helicobacter pylori cause an intense vacuolar degeneration of cells, due to the enlargement of late endosomes in the presence of membrane permeant weak bases. Bafilomycins, specific inhibitors of the vacuolar-type (V-) ATPase proton pump, prevent vacuole formation. The presence of the V-ATPase on vacuolar membranes was demonstrated by immunofluorescence with a monoclonal antibody (MAb) specific for the human 116-kDa regulatory subunit. The V-ATPase co-localised with the late endosomal marker rab7 on vacuolar membranes. In contrast, the early recycling endosomal compartment was not altered by the VacA cytotoxin, although it was endowed with the V-ATPase. Endocytosis of a MAb against the 116-kDa regulatory subunit of V-ATPase blocked endosomal acidification in HeLa cells and prevented VacA action. These results indicate that selective swelling of late endosomes, due to accumulation of osmotically active weak bases driven by the V-ATPase, is essential for vacuole formation.
\end{abstract}

\section{Introduction}

Prolonged stomach infection with Helicobacter pylori is a major determinant in the development of gastroduodenal ulcers and of stomach adenocarcinoma in man [1-7]. Different virulence factors allow $H$. pylori to colonise the extremely acidic intragastric environment. Primarily, a potent urease expressed on the bacterial surface is believed to neutralise the local environment of the bacterial cell by splitting urea into carbon dioxide and ammonia, thus permitting its survival in the gastric juice $(\mathrm{pH} 1.5-2.0)$ [8]. Flagella, mucolytic proteases and specific adhesins $[9,10]$ allow $H$. pylori to penetrate into the mucus layer coating the gastric walls and to bind to gastric epithelial cells. $H$. pylori manifests great genetic variability. The majority of strains isolated from human ulcer biopsies produce two additional proteins, a cytotoxin that causes cell vacuolisation (VacA) and an immunodominant cytotoxin-associated antigen (CagA) of unknown function [1114]. Purified VacA administered to mice determines a degeneration of gastric epithelial cells similar to that observed in ulcers in man [13]. In cultured cells, VacA induces the formation and growth of numerous translucent vacuoles that originate from the perinuclear

Received 3 Aug. 1995; accepted 12 Dec. 1995. Corresponding author: Dr E. Papini. region and rapidly fill up all the cell cytoplasm leading to cell death [14]. VacA is produced as a $140-\mathrm{kDa}$ protein with a $46-\mathrm{kDa} \mathrm{COOH}$-terminal domain, presumably involved in toxin translocation similarly to $\lg$ A-proteases [15-19]. The amino-terminal 94-kDa protein is released into the medium [15]. Previous studies have shown that vacuoles induced by $\mathrm{VacA}$ are highly enriched in rab7, a small GTP-binding protein mainly associated with late endosomes [20]. These intracellular compartments are endowed with a vacuolar-type (V-) ATPase proton pump which is responsible for their intralumenal acidic pH [21]. V-ATPase is an electrogenic proton pump, present on several eukaryotic intracellular compartments, located at different stages along either the endocytic or the exocytic pathways [22]. This membrane bound complex hydrolyses ATP to pump protons into the lumen of membrane delimited compartments [21]. Bafilomycins, powerful inhibitors of the V-ATPase [23], prevent vacuole formation and are also able to cause already vacuolated cells to revert to an apparently normal phenotype [24-26].

This study examined $H$. pylori for the presence of the V-ATPase on the vacuolar membrane and for its localisation in relation to $\mathrm{rab} 7$ in the presence or absence of ammonia, as a protonable membrane permeant substance. The effect of OSW2, a monoclonal antibody (MAb) specific for the $116-\mathrm{kDa}$ 
regulatory subunit of V-ATPase, on VacA-induced cell vacuolation was also studied.

\section{Materials and methods}

\section{Antibodies and proteins}

Mouse MAb against the regulatory subunit (116 kDa) of human V-ATPase, termed OSW2, was characterised and described previously [27]. Guinea-pig polyclonal antibodies against subunit $\mathrm{A}$ and rabbit polyclonal antibodies against subunit B of V-ATPase were gifts from N. Nelson (Roche Institute of Molecular Biology, Nutley, USA). Rabbit polyclonal antibody to rab7 was a kind gift of M. Zerial (EMBL, Germany). Human holotransferrin, goat anti-human transferrin antibodies, rhodamine- and FITC-modified secondary antibodies were purchased from Sigma. VacA was purified from the $H$. pylori cytotoxic strain CCUG 17874 as described previously [28]. Purified VacA $(1 \mu \mathrm{M}$ in PBS) was frozen with liquid nitrogen and stored in small volumes at $-70^{\circ} \mathrm{C}$.

\section{Cell culture}

HeLa cells were cultured in plastic flasks in Dulbecco's modified minimal essential medium (DMEM), containing $\mathrm{FCS} 10 \%$ in air with $\mathrm{CO}_{2} 5 \%$ at $37^{\circ} \mathrm{C}$.
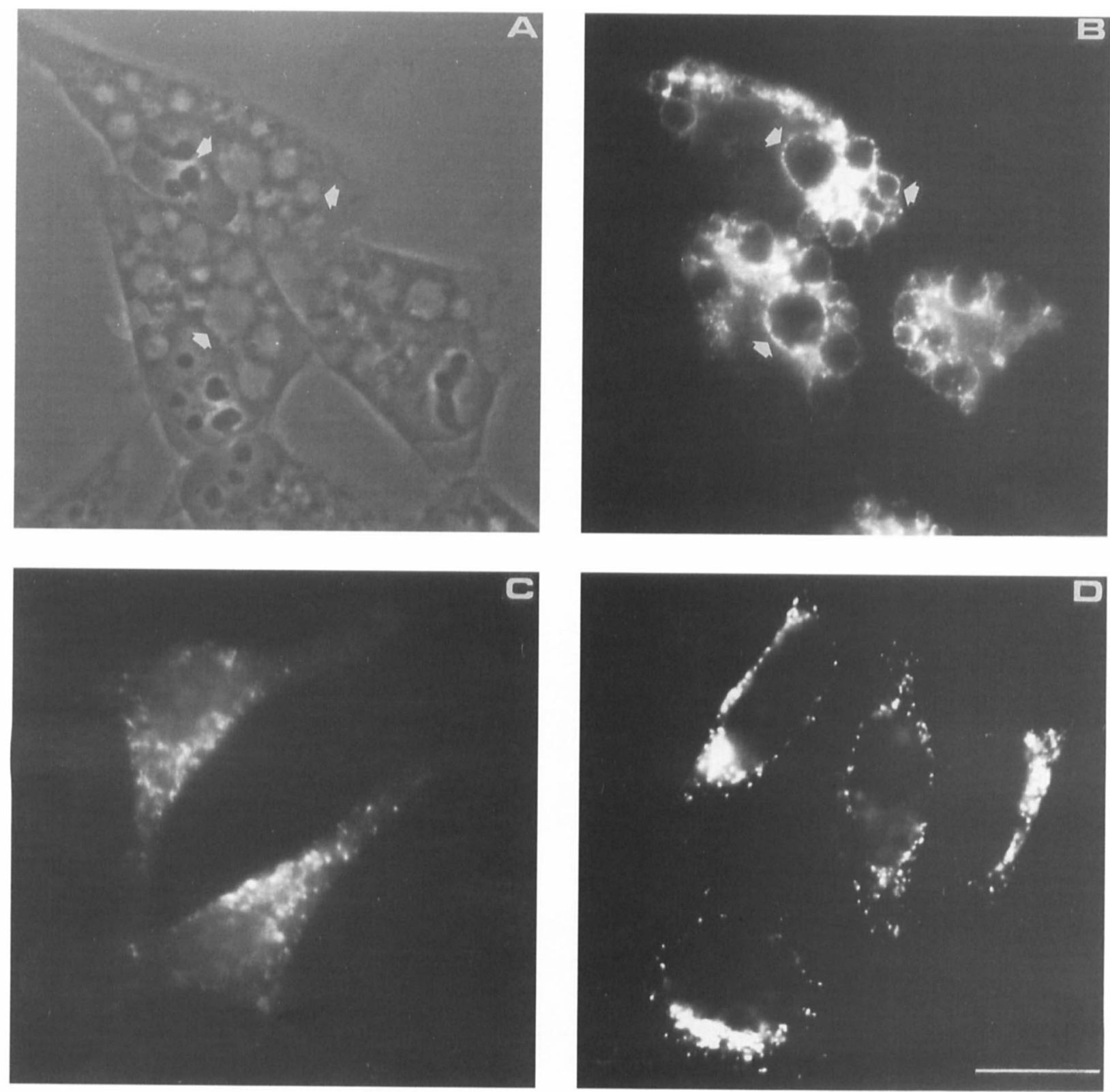

Fig. 1. Intracellular distribution of V-ATPase in HeLa cells treated with VacA in the presence or absence of $\mathrm{NH}_{4} \mathrm{Cl}$. HeLa cells were grown on coverslips and treated for $24 \mathrm{~h}$ with $0.1 \mu \mathrm{M}$ VacA in the presence (A, B) or in the absence (c) of $5 \mathrm{mM} \mathrm{NH}_{4} \mathrm{Cl} ; \mathbf{D}$, unintoxicated cells. V-ATPase is revealed by indirect immunofluorescence staining with MAb OWS2 ( 1 in 1000) and rhodamine-conjugated anti-mouse antibody $(1$ in 100$)(B, C, D) ; \rightarrow$, typical examples of membranes delimiting VacA-induced vacuoles. Bar $10 \mu \mathrm{M}$. 


\section{Intoxication}

Cells grown on glass coverslips for $24 \mathrm{~h}$, were treated with $0.1 \mu \mathrm{M}$ VacA in DMEM, FCS $2 \%$, supplemented with $5 \mathrm{mM} \mathrm{NH}_{4} \mathrm{Cl}$ for $8-18 \mathrm{~h}$ or left untreated. $\mathrm{NH}_{4} \mathrm{Cl}$ was omitted when indicated. In some experiments, cells were washed with serum-free DMEM, incubated with $1 \mu \mathrm{M}$ human holotransferrin for $1 \mathrm{~h}$ in the same medium and then treated with VacA as above in the presence of transferrin for $8 \mathrm{~h}$. In some experiments, ascitic fluid containing MAb OWS2 was diluted serially in DMEM, FCS $2 \%$ and incubated with HeLa cells for $1 \mathrm{~h}$ at $37^{\circ} \mathrm{C}$ before the addition of $0.1 \mu \mathrm{M}$ VacA and $5 \mathrm{mM} \mathrm{NH} \mathrm{NH}_{4}$ or of $\mathrm{NH}_{4} \mathrm{Cl}$ alone. Vacuolation was quantified by neutral red uptake [14].
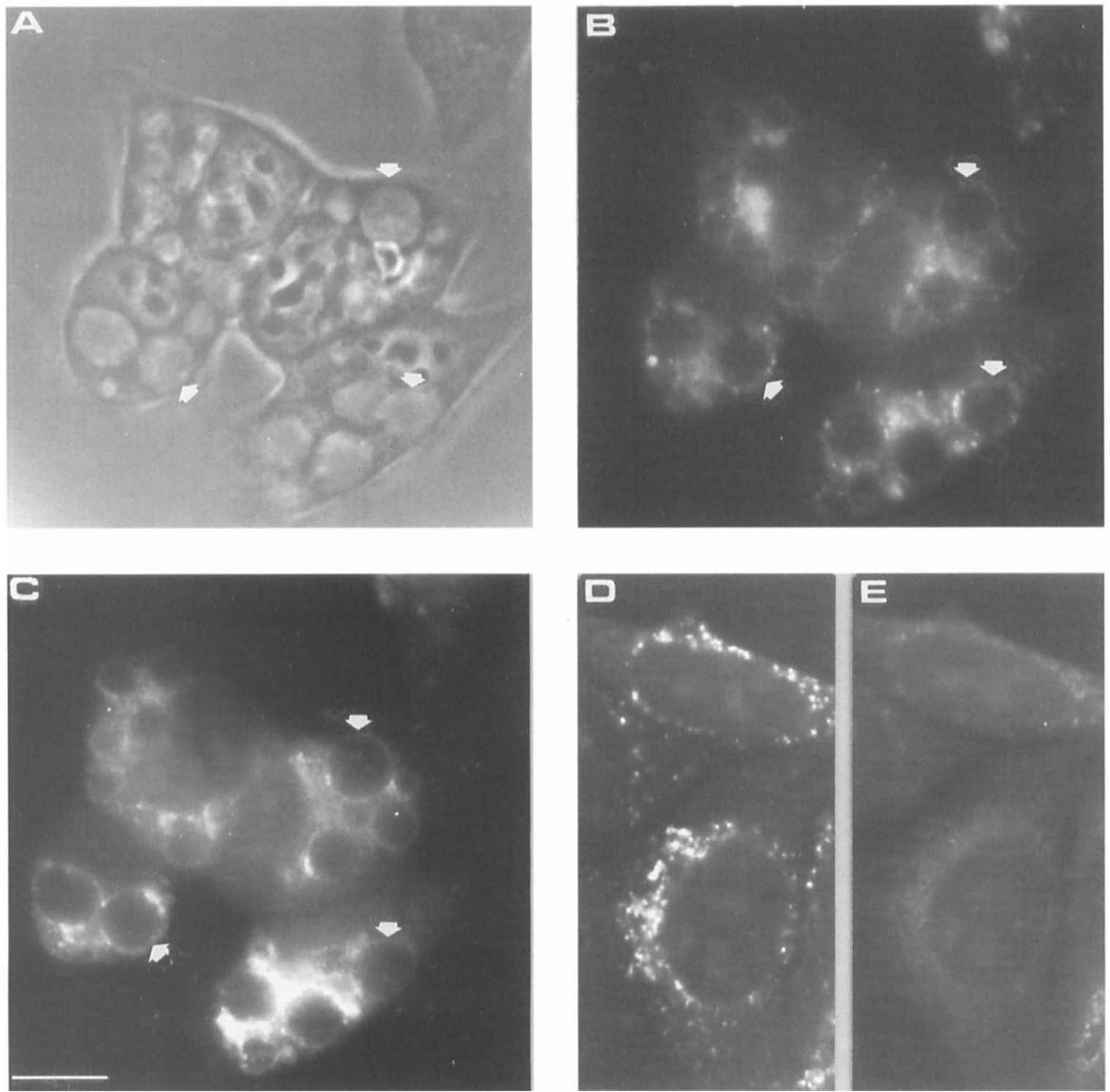

\section{Fluorescence microscopy}

For immunofluorescence, cells were fixed with paraformaldehyde $3 \%$ for $20 \mathrm{~min}$, treated with $\mathrm{NH}_{4} \mathrm{Cl}$, $0.27 \%$ glycine $0.38 \%$ for $10 \mathrm{~min}$ and permeabilised with saponine $0.2 \%$, BSA $0.5 \%$ in PBS for $30 \mathrm{~min}$. Primary antibodies were diluted in the permeabilisation medium and applied to cells for $1 \mathrm{~h}$. After several washes, rhodaminated or fluoresceinated secondary antibodies were added, incubated for a further $30 \mathrm{~min}$ in the same medium and then washed. Samples were mounted in glycerol $90 \%, \mathrm{~N}$-propylgallate $0.2 \%$ in PBS and observed by fluorescence microscopy (Zeiss Axioplan, Jena, Germany).

Fig. 2. Co-localisation of V-ATPase and rab7 on the membrane of intracellular vacuoles due to VacA. HeLa cells were grown on coverslips and treated $(\mathbf{A}, \mathbf{B}, \mathbf{C})$ or not $(\mathbf{D}, \mathbf{E})$ with $\mathrm{VacA}$ in the presence of $5 \mathrm{mM} \mathrm{NH}{ }_{4} \mathrm{Cl}$. After fixation and permeabilisation, cells were stained with MAb OWS2, (1 in 1000) (B, D) and with rabbit polyclonal antibodies to rab7 ( 1 in 200) (C, E), followed by incubation with either FITC-conjugated anti-rabbit IgC, or rhodamine-conjugated antimouse $\operatorname{lgG}$, respectively; A, light microscopy view of the same field; $\rightarrow$, representative vacuolar membranes. Bar $10 \mu \mathrm{m}$. 


\section{Results}

Immunostaining of HeLa cells exposed to VacA with OSW2 showed that V-ATPase was associated with the membrane of intracellular vacuoles in HeLa cells (Fig. 1). The comparison with the phase-contrast micrograph (Fig. 1A) shows that every vacuole contained V-ATPase (Fig. 1B). Immunostaining with antibodies recognising either subunit A or subunit B of V-ATPase gave similar results, confirming the presence of the whole V-ATPase complex on the vacuolar membrane (data not shown). These results provide the first direct evidence of the presence of the V-ATPase on vacuoles induced by VacA. The neat and intense V-ATPase staining showed a patchy distribution, suggesting a clustering of enzymic complexes on the vacuolar membrane. When highly purified urease-free VacA was used, vacuole growth depended strictly on the presence of $\mathrm{NH}_{4}^{+}$ions, at a concentration $(5 \mathrm{mM})$ which by itself had no swelling effect on cell acidic compartments. In fact, without $\mathrm{NH}_{4}^{+}$, VacA treated cells did not develop vacuoles and V-ATPase positive compartments appeared to have a physiological size (Fig. 1C), indistinguishable from those of control cells (Fig. 1D). In vacuolated cells, the V-ATPase staining was not restricted to the vacuolar membrane, but was also present on smaller vesicles unaffected by VacA.

In Fig. 2 the intracellular distribution of V-ATPase is compared with that of rab7. In control cells this smallGTP binding protein, a marker of late endosomes [29], had a punctate perinuclear distribution, partially superimposed with that of V-ATPase (Fig. 2D and E). Clearly, V-ATPase and rab7 co-localised on the membrane of vacuoles induced by VacA, confirming that they had arisen from late endosomes (Fig. 2B and C). This is also indicated by the absence from vacuoles of transferrin, a well characterised marker of early endosomes or recycling compartment [30], as shown in Fig. 3. Only after prolonged exposures to high doses of Vac A did a minor fraction of vacuoles stain faintly for transferrin; this may have resulted

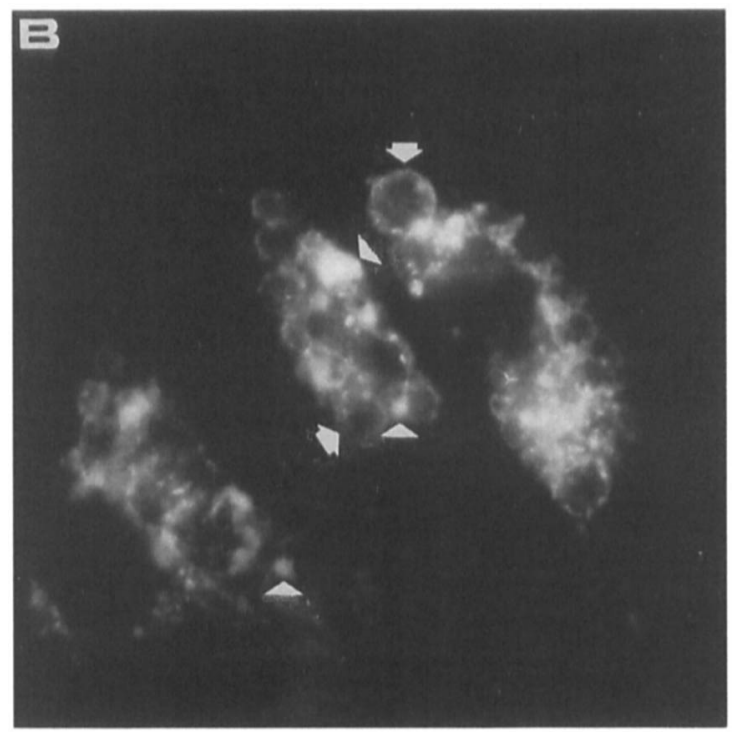

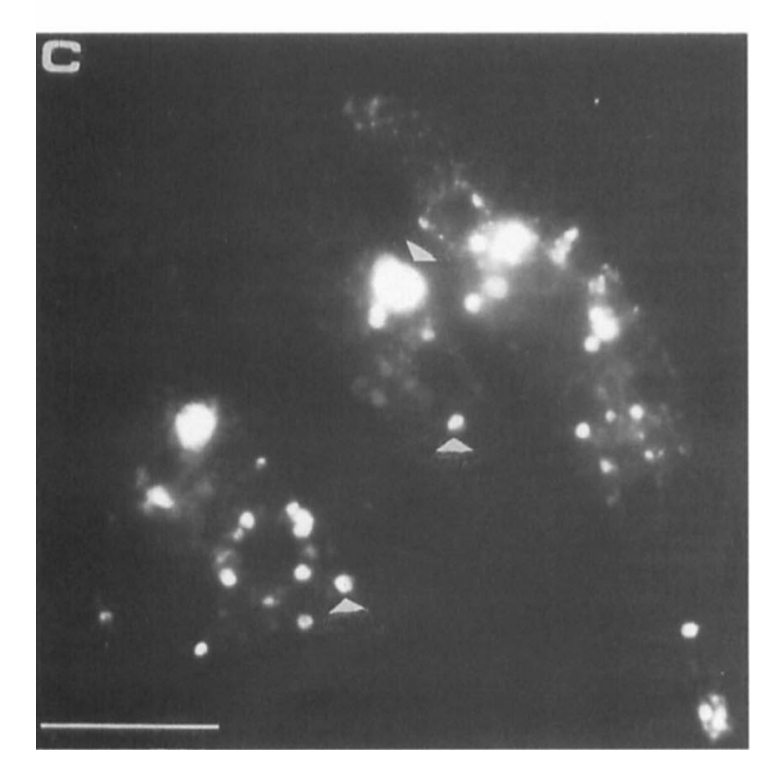

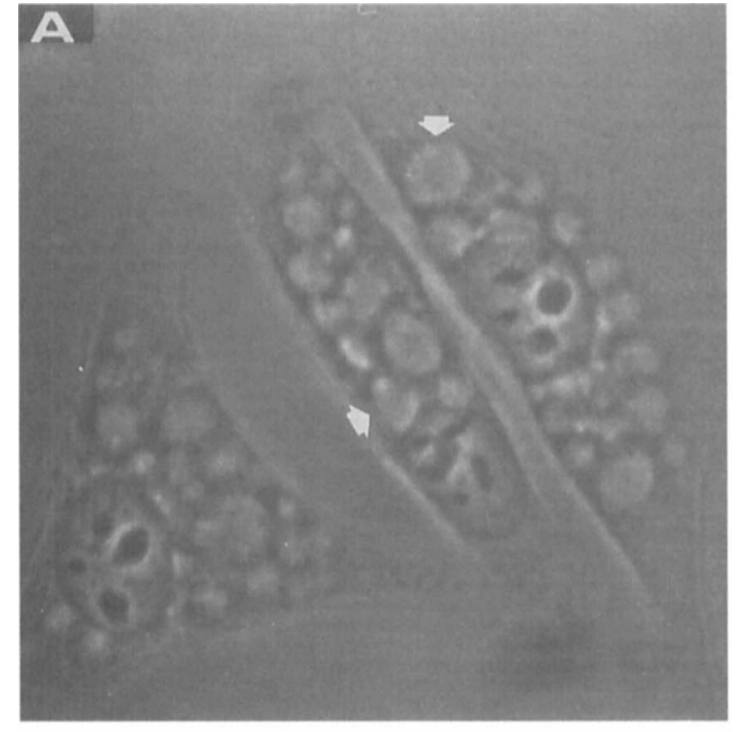

Fig. 3. Intracellular distribution of transferrin and of VATPase in vacuolated HeLa cells. HeLa cells were incubated for $1 \mathrm{~h}$ with $1 \mu \mathrm{M}$ human holotransferrin, and with $0.1 \mu \mathrm{M} \mathrm{VacA}$ in the presence of transferrin for $8 \mathrm{~h}$. (A) Light microscopy; (B) V-ATPase and (C) transferrin demonstrated by indirect double immunofluorescence; $\rightarrow$, vacuolar membranes; $\rightarrow$, early endosomes, where both VATPase and transferrin are present. Bar $10 \mu \mathrm{m}$. 
from a small amount of spill-over from early into late endosomes or to heterotypic fusions between endosomes.

The active involvement of V-ATPase in vacuolation was demonstrated by the inhibitory action of MAb OSW2, previously shown to inhibit endosomal acidification [27], on VacA action (Fig. 4). HeLa cells were treated with different concentrations of MAb OSW2 for $1 \mathrm{~h}$, a time sufficient to load late endosomes (data not shown), and then exposed to VacA. OSW2 prevented vacuolation and basal neutral red uptake in endolysosomes at very similar antibody dilutions ( 1 in 180 and 1 in 190, respectively), indicating that vacuolation required a functionally active V-ATPase.

\section{Discussion}

VacA is a major $H$. pylori virulence factor implicated in the pathogenesis of gastric and duodenal chronic inflammation and ulcer. Strains that do not release VacA, or cytotoxic strains whose vacA gene has been inactivated, do not cause cell vacuolisation [16, 17]. Vacuolar cell degeneration leads to death with release of necrotic factors chemotactic for polymorphonuclear leucocytes, which are always present in the infected stomach mucous membrane. Hence, clarification of the molecular mechanism of cell intoxication by VacA has recently become a major focus of research into the molecular pathogenesis of gastroduodenal ulcers $[6,7]$. The observations that the intracellular vacuoles induced by VacA accumulate the acidotropic compound neutral red and that their formation is inhibited by bafilomycins $[14,24-26]$ indicate that a V-ATPase supports an inward-directed proton flow. The MAb OSW2 recognises an epitope located on the luminal portion of the 116-kDa subunit of the V-ATPase [27], an integral membrane protein believed to regulate proton pumping activity [31]. In fact, MAb OSW2 binds to V-ATPase on the plasma membrane, is endocytosed and prevents acidification of the endosomal lumen, thus protecting cells from infection by some viruses [27 and our unpublished observations]. The present study provides the first direct evidence of the presence of V-ATPase on the vacuolar membrane and shows that it colocalises with rab7 on the vacuoles. The strong protective effect of MAb OSW2 with respect to VacA, which induced vacuolisation suggests that the $116-\mathrm{kDa}$ regulatory subunit of V-ATPase plays a key role in acidification of vacuoles. Moreover, it provides direct functional evidence of the role of the V-ATPase in vacuole growth, previously suggested by indirect data obtained with bafilomycins [24-26]. Taken together, these results indicate that compartment swelling and membrane flow disorders are both involved in VacAinduced cell vacuolisation. Ammonium ions are essential for vacuole formation, as V-ATPase positive compartments are not swollen in cells incubated with

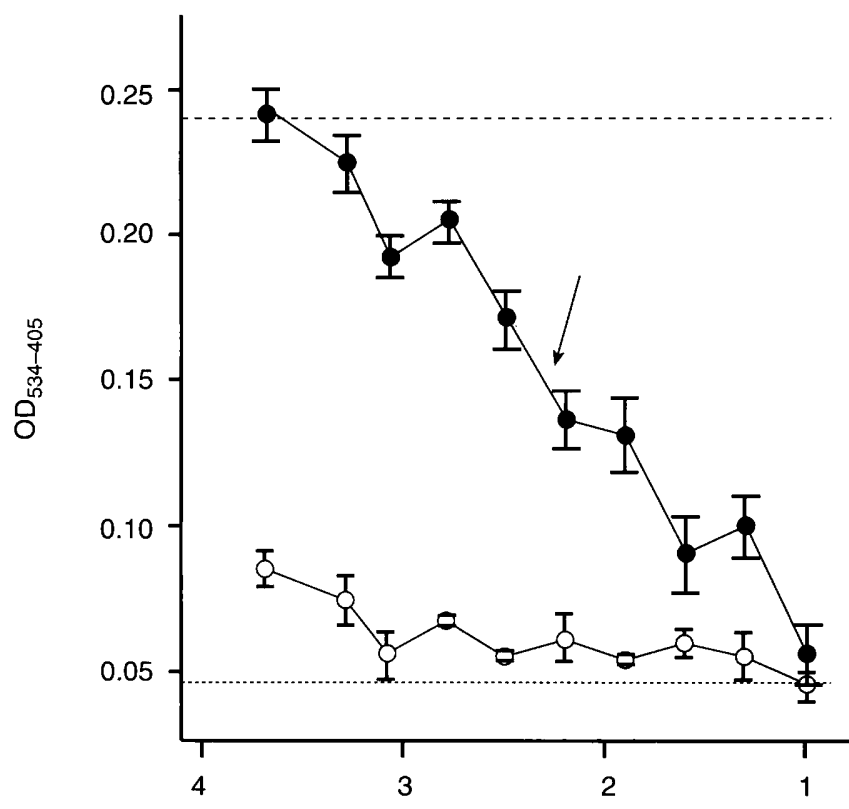

b

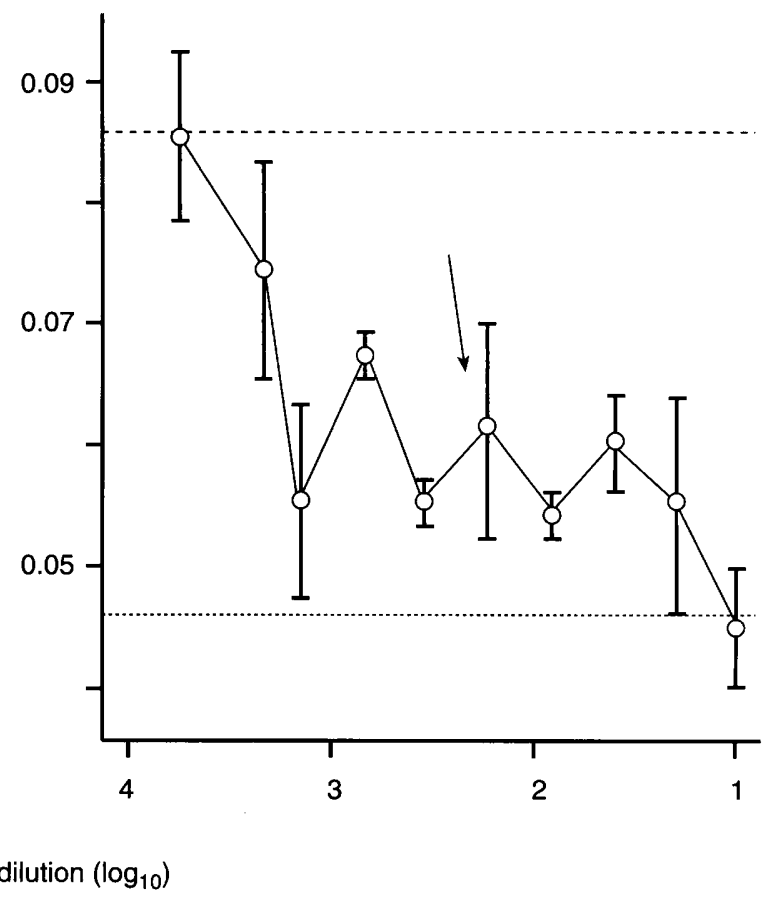

Fig. 4. Inhibition of VacA activity by a MAb against the 116-kDa regulatory subunit of V-ATPase. a, HeLa cells, preincubated for $1 \mathrm{~h}$ with various dilutions of OWS2 asciticfluid, were treated $(0)$ with $0.1 \mu \mathrm{M}$ VacA. Vacuolation was determined as neutral red uptake and expressed as optical density; $\mathbf{b}$, data referring to the basal uptake of the dye, a parameter of V-ATPase activity $(O)$, are amplified to allow comparison with the vacuolation extent;..-- and..... correspond to control and to background values, respectively. Antibody dilutions giving 50\% inhibition (ID50\%) are indicated. Values are the mean of triplicate samples and bars represent SE. 
VacA without $\mathrm{NH}_{4}^{+}$. Swelling of acidic compartments results from the accumulation of $\mathrm{NH}_{4}^{+}$, which follows the proton gradient, but this osmotic effect cannot account for the very large vacuoles observed. These vacuoles contain both the V-ATPase and rab7 indicating that VacA acts on late endosomes, a subset of acidic intracellular compartments [21]. This specificity is emphasised by the finding that the recycling compartment which pervades all the cytoplasm and is endowed with V-ATPase is not altered by VacA. To obtain the large vacuoles that precede cell death, it appears that extensive membrane fusion has to take place. We propose that VacA causes a specific impairment of cell membrane trafficking at the late endosomal level. Such a cell lesion, together with the osmotic swelling effect driven by the V-ATPase activity, results in vacuole formation and growth.

We thank Dr N. Nelson for antibodies to subunit A and B of VATPase. This work is in partial fulfillment of the Doctorate degree in Molecular and Cellular Biology and Pathology by M. de B.

\section{References}

1. Warren JR, Marshall BJ. Unidentified curved bacilli on gastric epithelium in active chronic gastritis. Lancet 1983; 1: 1273 1275

2. Marshall BJ. Armstrong JA, McGechie DB, Glancy RJ. Attempt to fulfil Koch's postulates for pyloric Campylobacter. Med $J$ Aust 1985; 142: 436-439.

3. Eurogast Study Group. An international association between Helicobacter pylori infection and gastric cancer. Lancet 1993 341: 1359-1362.

4. N. I. H. Consensus Development Panel on Helicobacter pylori in peptic ulcer disease. JAMA 1994; 272: 65-69.

5. Parsonnet J, Hansen S, Rodriguez L et al. Helicobacter pylori infection and gastric lymphoma. $N$ Engl $J$ Med 1994; 330: $1267-1271$

6. Blaser MJ. Helicobacter pylori: microbiology of a "slow" bacterial infection. Trends Microbiol 1993; 1: 255-260.

7. Telford JL, Covacci A, Ghiara P, Montecucco C, Rappuoli R Unravelling the pathogenic role of Helicobacter pylori in peptic ulcer: potential new therapies and vaccines. Trends Biotechnol 1994; 12: 420-426.

8. Eaton KA, Morgan DR, Krakowka S. Motility as a factor in the colonisation of gnotobiotic piglets by Helicobacter pylori. $J$ Med Microbiol 1992; 37: 123-127.

9. Lingwood CA. Helicobacter pylori: receptors and adhesins. In: Goodwin CS, Worsely BW (eds) Helicobacter pylori: biology and clinical practice. Boca Raton, FL, CRC Press. 1993: 209222.

10. Borén T, Falk P, Roth KA, Larson G, Normark S. Attachment of Helicobacter pylori to human gastric epithelium mediated by blood group antigens. Science 1993; 262: 1892-1895.

11. Covacci A, Censini S, Bugnoli $M$ et al. Molecular characterization of the $128-\mathrm{kDa}$ immunodominant antigen of Helico bacter pylori associated with cytotoxicity and duodenal ulcer. Proc Natl Acad Sci USA 1993; 90: 5791-5795.

12. Crabtree JE, Taylor JD, Wyatt JI et al. Mucosal IgA recognition of Helicobacter pylori $120 \mathrm{kDa}$ protein, peptic ulceration, and gastric pathology. Lancet 1991; 338: 332-335

13. Marchetti M, Aricò B, Burroni D, Figura N, Rappuoli R, Ghiara P. Development of a mouse model of Helicobacter pylori infection that mimics human disease. Science 1995; 267: 1655-1658.

14. Cover TL, Blaser MJ. Purification and characterization of the vacuolating toxin from Helicobacter pylori. J Biol Chem 1992; 267: $10570-10575$.

15. Telford JL, Ghiara P, Dell'Orco $M$ et al. Gene structure of the Helicobacter pylori cytotoxin and evidence of its key role in gastric disease. J Exp Med 1994; 179: 1653-1658.

16. Phadnis SH, Ilver D, Janzon L, Normark S, Westblom TU. Pathological significance and molecular characterization of the vacuolating toxin gene of Helicobacter pylori. Infect Immun 1994; 62: $1557-1565$.

17. Cover TL, Tummuru MKR, Cao P, Thompson SA, Blaser MJ. Divergence of genetic sequences for the vacuolating cytotoxin among Helicobacter pvlori strains. J Biol Chem 1994; 269: 10566-10573.

18. Schmitt W, Haas R. Genetic analysis of the Helicobacter pylori vacuolating cytotoxin: structural similarities with the $\lg \mathrm{A}$ protease type of exported protein. Mol Microbiol 1994; 12: 307-319.

19. Pugsley AP. The complete general secretory pathway in gramnegative bacteria. Microbiol Rev 1993; 57: 50-108.

20. Papini E, de Bernard M, Milia E et al. Cellular vacuoles induced by Helicobacter pylori originate from late endosomal compartments. Proc Natl Acad Sci USA 1994; 91: 9720-9724.

21. Mellman I, Fuchs R, Helenius A. Acidification of the endocytic and exocytic pathways. Ann Rev Biochem 1986; 55: $663-700$.

22. Nelson N. Organellar proton-ATPase. Curr Opin Cell Biol 1992; 4: 654-660.

23. Bowman EJ, Siebers A, Altendorf K. Bafilomycins: a class of inhibitors of membrane ATPases from microorganisms, animal cells, and plant cells. Proc Natl Acad Sci USA 1988; 85: 7972-7976.

24. Papini E, Bugnoli M, de Bernard M, Figura N, Rappuoli R, Montecucco C. Bafilomycin Al inhibits Helicobacter pyloriinduced vacuolization of HeLa cells. Mol Microbiol 1993; 7: 323-327.

25. Papini E, de Bernard M, Bugnoli M, Milia E, Rappuoli R, Montecucco $\mathrm{C}$. Cell vacuolization induced by Helicobacter pylori: inhibition by bafilomycins A1, Bl, Cl, and D. FEMS Microbiol Lett 1993; 113: 155-159.

26. Cover TL, Reddy LY, Blaser MJ. Effects of ATPase inhibitors on the response of HeLa cells to Helicobacter pylori vacuolating toxin. Infect Immun 1993; 61: 1427-1431.

27. Sato SB, Toyama S. Interference with the endosomal acidification by a monoclonal antibody directed toward the $116(100)-\mathrm{kD}$ subunit of the vacuolar type proton pump. $J$ Cell Biol 1994; 127: 39-53.

28. Manetti R, Masari P, Burroni D et al. Helicobacter pylori cytotoxin: importance of native conformation for induction of neutralizing antibodies. Infect Immun 1995; 63: 4476-4480.

29. Chavrier P, Parton GR, Hauri HP, Simons K, Zerial M. Localization of low molecular weight GTP binding proteins to exocytic and endocytic compartments. Cell 1990; 62: 317-329.

30. Hopkins CR, Trowbridge IS. Internalization and processing of transferrin and the transferrin receptor in human carcinoma A431 cells. J Cell Biol 1983; 97: 508-521.

31. Perin MS, Fried VA, Stone DK, Xie XS, Sudhof TC. Structure of the 116-kDa polypeptide of the chlatrin-coated vesicle synaptic vesicle proton pump. J Biol Chem 1991; 266: $3877-$ 3881 . 